\title{
Adult mesenchymal stem cells for bone and cartilage engineering: effect of scaffold materials
}

A. Gigante, ${ }^{1,2}$ S. Manzotti, ${ }^{2}$ C. Bevilacqua, ${ }^{1}$ M. Orciani, ${ }^{3}$ R. Di Primio, ${ }^{3}$ M. Mattioli-Belmonte ${ }^{3}$ ${ }^{1}$ Clinica Ortopedica, Facoltà di Medicina e Chirurgia, Università Politecnica delle Marche, Ancona; ${ }^{2}$ Dipartimento di Patologia Molecolare e Terapie Innovative Facoltà di Medicina e Chirurgia, Università Politecnica delle Marche, Torrette, Ancona; ${ }^{3}$ Dipartimento di Patologia Molecolare e Terapie Innovative Istologia, Facoltà di Medicina e Chirurgia, Università Politecnica delle Marche, Torrette, Ancona, Italy

(C)2008 European Journal of Histochemistry

Bone marrow is a useful cell source for skeletal tissue engineering approaches. In vitro differentiation of marrow mesenchymal stem cells (MSCs) to chondrocytes or osteoblasts can be induced by the addition of specific growth factors to the medium. The present study evaluated the behaviour of human MSCs cultured on various scaffolds to determine whether their differentiation can be induced by cell-matrix interactions.

MSCs from bone marrow collected from the acetabulum during hip arthroplasty procedures were isolated by cell sorting, expanded and characterised by a flow cytometry system. Cells were grown on three different scaffolds (type I collagen, type I + II collagen and type I collagen + hydroxyapatite membranes) and analysed by histochemistry, immunohistochemistry and spectrophotometry (cell proliferation, alkaline phosphatase activity) at 15 and 30 days.

Widely variable cell adhesion and proliferation was observed on the three scaffolds. MSCs grown on type I+II collagen differentiated to cells expressing chondrocyte markers, while those grown on type I collagen + hydroxyapatite differentiated into osteoblast-like cells.

The study highlighted that human MSCs grown on different scaffold matrices may display different behaviours in terms of cell proliferation and phenotype expression without growth factor supplementation.

Key words: cartilage, bone, tissue engineering, human mesenchymal stem cell, collagen.

Correspondence: Monica Mattioli-Belmonte,

Dipartimento di Patologia Molecolare,

e Terapie Innovative-Istologia,

Università Politecnica delle Marche,

Via Tronto 10/A 60020 Ancona, Italy.

Tel.: +39.071.2206 077 .

Tel.: +39.071.2206 073.

E-mail:m.mattioli@univpm.it

Paper accepted on July 10, 2008

European Journal of Histochemistry

2008; vol. 52 issue 3 (July-September): 169-174
T issue engineering is one of the most promising therapeutic approaches to bone and cartilage repair. Tissue engineering techniques allow to repair or replace damaged skeletal tissue with autologous or allogenic cells. Despite the positive results obtained in the clinical treatment of cartilage lesions (Peterson et al., 2000), the use of terminally differentiated cells is hampered by the limited sources of normal tissue for harvesting, donor site morbidity, the poor duplicative capacity of chondrocytes and their trend to de-differentiate in vitro (Elisseeff, 2004). Treatment of bone defects with autologous bone grafts is associated with morbidity (pain, blood loss, surgical scars), besides the possibility of insufficient graft material (Younger and Chapman, 1989).

Stem cells are a particularly attractive cell type for tissue engineering applications. Their unique high self-renewal activity and multilineage differentiation potential make them an ideal source for cell therapy and regenerative medicine. Adult marrow mesenchymal stem cells (MSCs) (Caplan, 1994) are multipotent cells that are able to generate cartilage, bone and fat (Pittinger et al., 1999; Prockop, 1997). MSCs are easily isolated from human bone marrow (BM) and expanded in culture (Bruder et al., 1997; Gerson, 1999); BM is therefore a good source of cells for skeletal tissue engineering (Kassem and Abdallah, 2008). MSCs do not differentiate spontaneously in culture (Pittinger et al., 1999) nor do they have a progressive commitment towards the osteogenic lineage (Banfi et al., 2002). Their differentiation to tissuespecific cells requires the addition of induction agents and/or appropriate culture conditions (Trubiani et al., 2005; Reyes et al., 2001; Wang et al., 2007; Yoo et al., 1998). Chondroblasts and osteoblasts have been obtained in vitro by use of growth factors like basic fibroblast growth factors (bFGF), transforming growth factor-beta (TGF- $\beta$ ) 
and bone morphogenetic protein-2 (BMP-2) (Kipnes et al., 2003; Mastrogiacomo et al., 2001; Pittinger et al., 1999).

According to a relatively novel tissue-engineering concept, scaffolds can be designed in such a way as to induce stem cell (or precursor cell) differentiation to a specific phenotype at the implantation site. Cells can therefore be expanded in vitro and differentiated into diverse cell types through the action of biomaterial properties such as chemistry, surface energy, wettability, roughness, and topography (Chai and Leong, 2007).

The demonstration that cell-matrix interactions exert a major influence on the behaviour of differentiated cells for tissue engineering (Datta et al., 2005; Gigante et al., 2003) and that surface chemistry is capable of modulating MSC behaviour (Landi and Tampieri, 2006; MattioliBelmonte et al., 2005) prompted us to investigate to what extent cell-matrix interactions influence the in vitro behaviour of human MSCs cultured on different scaffold matrices.

\section{Materials and Methods}

\section{Mcs isolation and characterisation}

BM was collected from acetabulum and femoral head of 6 patients (mean age 59 years) undergoing total hip arthroplasty, who gave their informed consent. BM mononuclear cells were obtained by Histopaque $^{\circledR} 1077$ (Sigma Aldrich, MO, USA) density gradient centrifugation. Cells were plated in $25 \mathrm{~cm}^{2}$ culture flasks (Falcon ${ }^{\oplus}$, Becton Dickinson Labware, NJ, USA) in MesenCult ${ }^{\mathrm{TM}}$ Basal Medium supplemented with Mesenchymal Stem Cell Stimulatory Supplements (StemCell Technologies Inc., BC, Canada) and $1 \%$ penicillinstreptomycin (Gibco Invitrogen, Scotland, UK) for 14 days. Near-confluence cultures were then trypsinised (Trypsin-EDTA 1X -Gibco Invitrogen), expanded (split ratio 1:3) through sequential passages and finally used at the $5^{\text {th }}$ passage.

Cells were characterised using the FACSCalibur flow cytometry system (Becton Dickinson, CA, USA) in line with International Society for Cellular Therapy guidelines (Dominici et al., 2006) using antibodies against the following surface antigens: HLA-DR, CD34, CD105, CD14, CD19 and CD45 (Diaclone, France), CD73 and CD90 (StemCell Technologies Inc.).

\section{Cell cultures on membranes}

Three commercial collagen membranes, type I collagen (group A), type I + type II collagen (group B) and type I collagen + hydroxyapatite (HA) (group C) manufactured by Opocrin SpA, Italy) were used.

Cells were seeded on the membranes at an initial density of $2 \times 10^{4} / \mathrm{cm}^{2}$ and cultured in 24-well plastic culture plates (Nunc A/S, Denmark) for 30 days. Cells grown on polystyrene served as the control group. Cultures were grown in Dulbecco Modified Essential Medium (DMEM), 10\% foetal bovine serum (FBS) and $1 \%$ penicillin-streptomycin (all from Gibco Invitrogen), in 5\% $\mathrm{CO} 2$ atmosphere. The medium was replaced at 48-h intervals.

Cell proliferation and alkaline-phosphatase (ALP) production were assayed spectrophotometrically at 15 and 30 days. Histochemical and immunohistochemical analyses were performed at 30 days to study phenotype expression and cell adhesion.

\section{Cell growth}

Cell proliferation was evaluated 15 and 30 days into culture by measuring the number of viable cells using the MTT (3-dimethylthiazol-2,5-diphenyltetrazolium bromide) colorimetric assay. In brief, the medium was removed, $200 \mu \mathrm{L}$ MTT (SIGMA M56655) solution ( $5 \mathrm{mg} / \mathrm{mL}$ in DMEM without phenol red) and $1.8 \mathrm{~mL}$ DMEM without phenol red was added to the monolayers; the multi-well plates were incubated at $37^{\circ} \mathrm{C}$ for a further $4 \mathrm{~h}$. After discarding the supernatants, the dark blue formazan crystals were dissolved by adding $2 \mathrm{~mL}$ of solvent ( $0.1 \mathrm{~N} \mathrm{HCl}$ in absolute isopropanol) and quantified spectrophotometrically (UV/Vis Lambda 3 Perkin Elmer, MA, USA) at $570 \mathrm{~nm}$. The results are reported as the percentage of viable cells compared with control cultures (100\%). Experiments were performed in triplicate.

\section{Alkaline phosphatase activity}

Alkaline phosphatase ALP production was measured at 15 and 30 days on cell lysates with 104 kit (Sigma-Aldrich, Italy) according to the manufacturer's recommendations. Values were calculated from optical absorbance at $420 \mathrm{~nm}$ and expressed as international units of enzyme activity per $\mathrm{ml}$ $(\mathrm{IU} / \mathrm{mL})$. Determinations were performed in triplicate. 


\section{Histochemistry and immunohistochemistry}

Samples were fixed in $4 \%$ paraformaldehyde in $0.1 \mathrm{M}$ phosphate buffer, $\mathrm{pH} 7.4$, at $4^{\circ} \mathrm{C}$ for $20 \mathrm{~min}$ and washed three times with phosphate-buffered saline (PBS). Histochemical analysis was performed with safranin $0, A L P$ and von Kossa stains.

For immunohistochemistry, non-specific binding was blocked with 3\% normal goat serum in PBS, $\mathrm{pH}$ 7.4, for $30 \mathrm{~min}$ at room temperature; slides were then incubated overnight with primary antibodies at $4^{\circ} \mathrm{C}$. Sections were incubated with polyclonal anti S-100 protein (DakoCytomation Denmark A/S, Glostrup DK) diluted 1:3000; anticollagen type I antibodies (Monosan, The Netherlands) at 1:150; monoclonal anti-chondroitin sulphate (chondroitin-S) antibodies (Sigma Aldrich, MO, USA) at 1:200; anti-collagen type II (Oncogene, CA, USA) $10 \mu \mathrm{g} / \mathrm{mL}$, and antiosteonectin (Biodesign Int, ME, USA) 10 nM. Rabbit and mouse immunoglobulins at the same dilutions as the primary antibodies were used as controls. After three washes with Tris- $\mathrm{HCl}(0.05 \mathrm{M}$, $\mathrm{pH}$ 7.6), the immune reaction was visualised with Dako LSAB+ system - HRP (DakoCytomation Denmark A/S, Glostrup DK) and observed with a Leica microscope (Leica Cambridge Ltd., UK) equipped with a digital camera.

\section{Statistical analysis}

Means and standard deviation (SD) were obtained from sums of three different experiments. Data were analysed by one-way ANOVA, Bonferroni's test and Student's t test. Statistical significance was tested at $p<0.05$

\section{Results}

\section{Cell growth}

The MTT colorimetric assay evidenced an increased number of viable cells with time in all groups (Figure 1). Group C (type I collagen + HA) membranes showed a significant $(p<0.05)$ increase in cell proliferation compared with groups $A$ (type I collagen) and B (type I + II collagen) both at 15 and at 30 days.

\section{Alkaline phosphatase activity}

A significant $(p<0.05)$ increase in ALP activity was detected in groups $A$ and $C$ compared with the control group (Figure 2). In group B differences

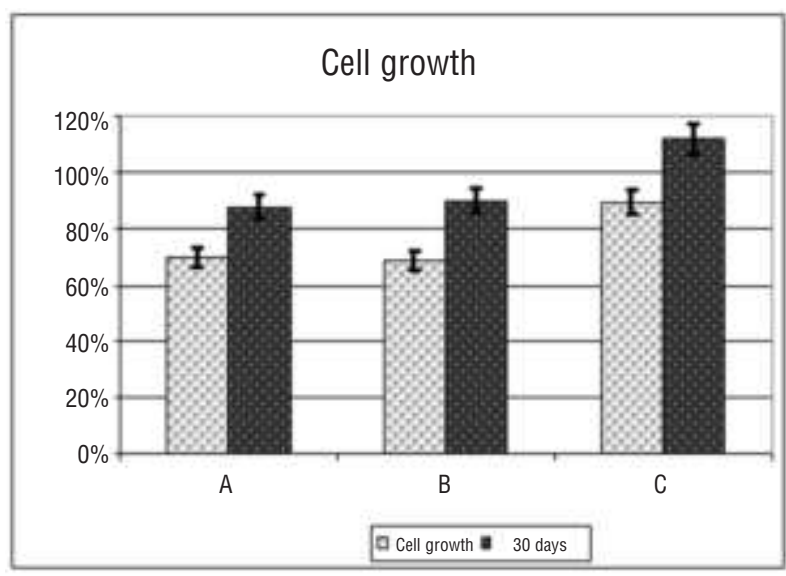

Figure 1. MSC proliferation on different scaffold matrices 15 and $\mathbf{3 0}$ days into culture (mean \pm SD). Group A: type I collagen membrane; group B: type I + II collagen membrane; group C: type I collagen + HA membrane. Control group: polystyrene.

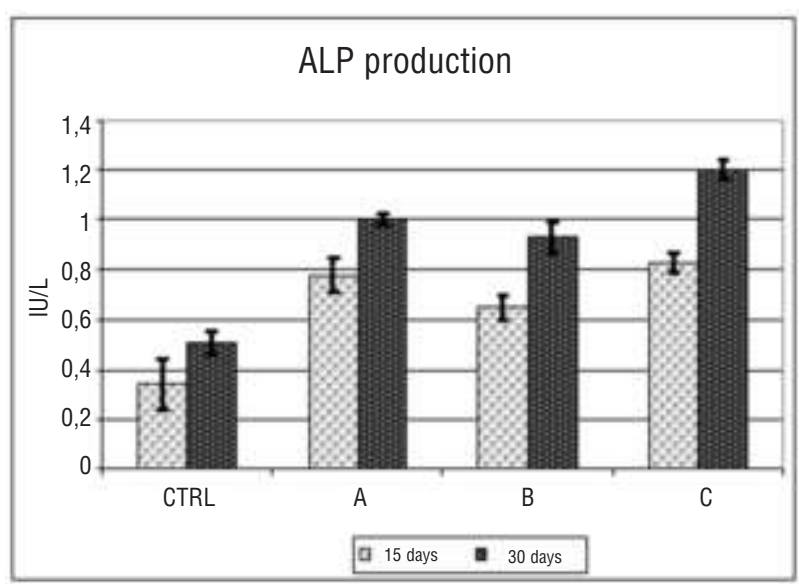

Figure 2. ALP production by MSCs grown on different scaffold matrices at 15 and 30 days. Group A: type I collagen membrane; group B: type I + II collagen membrane; group C: type I collagen + HA membrane. Control group: polystyrene.

from the control group were significant $(p<0.05)$ only at 30 days. ALP production was highest in group $C 30$ days into culture.

\section{Histochemistry and immunohistochemistry}

Control cells reached confluence and had a polymorphic appearance. Some cells exhibiting a strong ALP reaction were surrounded by numerous unstained cells. Staining for safranin 0 and von Kossa was seen only in some fields. Type I collagen immunostaining and mild chondroitin-S expression were also observed. S-100 protein positivity was not detected. 
Group A cells stained weakly for safranin 0 and expressed type I collagen and chondroitin-S. The immunohistochemical reaction for S-100 protein was negative.

Group B monolayers displayed a metachromatic reaction to safranin 0 and clear S-100 protein (Figure 3), type II collagen and chondroitin-S (Figure 4) immunostaining.

In group $C$ von Kossa stain disclosed mineralised matrixand ALP staining was homogeneous. Cells were positive for osteonectin (Figure 5) and type I collagen and weakly positive for chondroitin-S.

\section{Discussion}

The use of MSCs for skeletal tissue engineering is based on their high proliferation rate and ability to differentiate to many cell types. Several growth factors, such as bFGF, TGF- $\beta$ and BMP-2 have been used to induce in vitro MSC differentiation (Barry et al., 2001; Johnstone et al., 1998; Kipnes et al., 2003; Mastrogiacomo et al., 2001) Medium composition (serum free vs FBS; low/high-glucose content; addition of $\beta$-glycerophosphate and dexamethasone) and culture conditions, including cell density and distribution (monolayer, pellet), have been demonstrated to affect MSC behaviour (Ciapetti et al., 2006; Muraglia et al., 2003; Reyes et al., 2001; Yoo et al., 1998).

Previous research on mature chondrocytes cultured on different collagen membranes has demonstrated that the biochemical composition of the scaffold matrix can influence cell behaviour (Gigante et al., 2003). Cell-matrix interactions may thus be an additional mechanism for modulation of MSC differentiation.

MSC chondrogenic differentiation has been obtained using gelatine-based resorbable sponges (Ponticiello et al., 2000), photopolymerizing polyethylene glycol-based hydrogel (Williams et al., 2003) and PLA/alginate amalgam (Caterson et al., 2002) supplemented with TGF- $\beta 1$ to the culture medium. MSCs adhering to bioceramic composites differentiated to an osteogenic lineage and achieved bone defect repair in some in vitro (Kadiyala et al., 1997; Landi and Tampieri, 2006) and in vivo studies (Cancedda et al., 2003; Kadiyala et al., 1997).

Recently, hyaluronan-based scaffolds have been used for in vitro commitment of human and rat MSCs; also in this study, however, acquisition of the

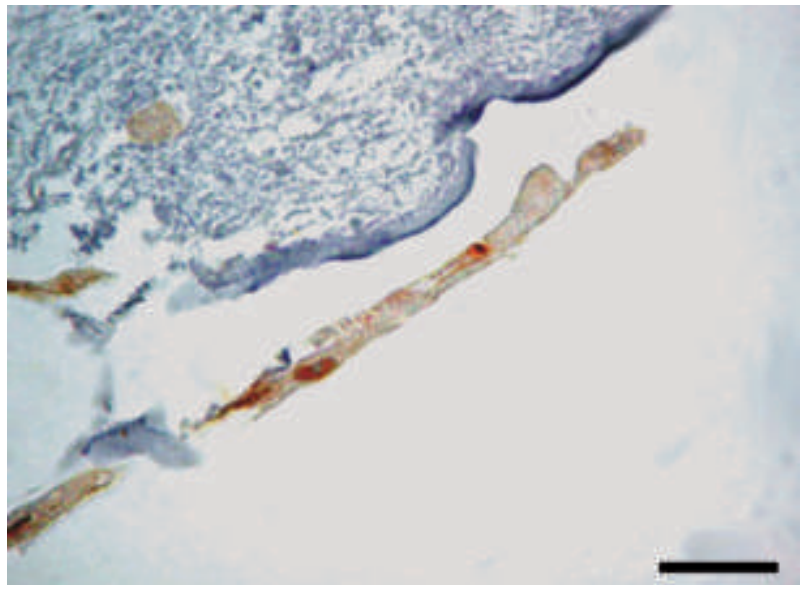

Figure 3. MSCs cultured on type I + II collagen membrane for 30 days. Positive immunoreaction for S-100 protein (scale bar $0.05 \mathrm{~mm})$.

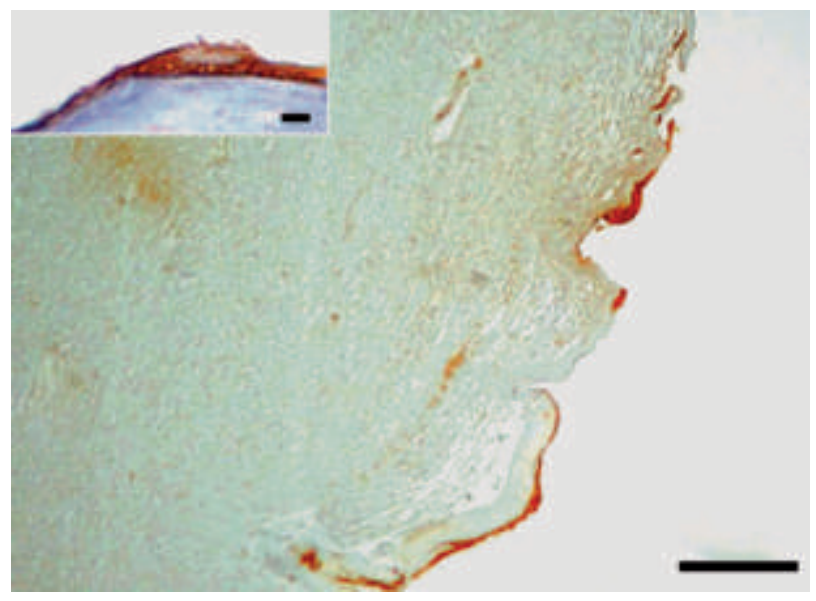

Figure 4. MSCs cultured on type I + II collagen membrane for 30 days. Cells positive for chondroitin-S adhering to the membrane (scale bar $0.1 \mathrm{~mm}$ ). Inset: positive cells in the scaffold (scale bar $10 \mathrm{um}$ ).

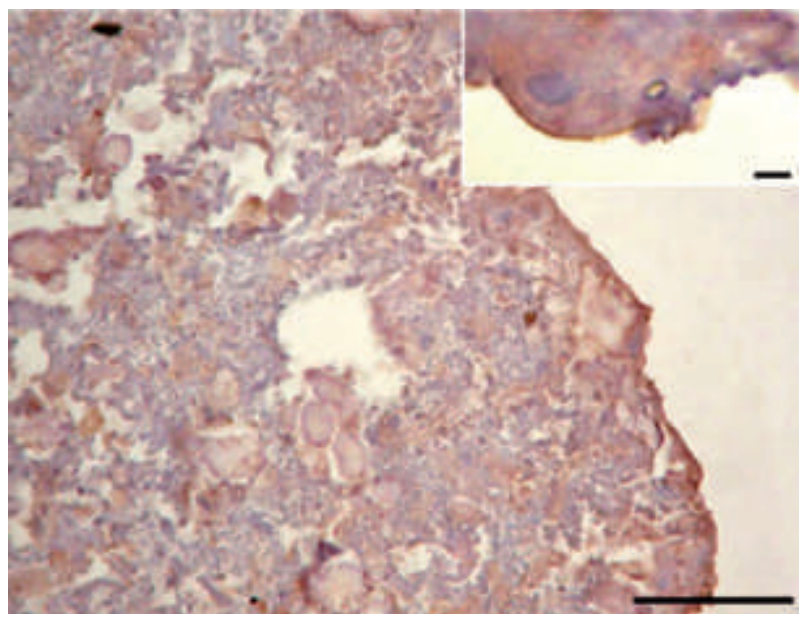

Figure 5. MSCs cultured on type I collagen + HA membrane for 30 days. Positive immunoreaction for osteonectin (scale bar 0,05 $\mathrm{mm}$ ). Inset high magnification displaying the immunostaining. 
specific chondrocytic and osteocytic phenotype depended on specific inducing factors added to culture media (Zavan et al., 2007).

The present study documents that human MSCs grown on different scaffold matrices may be induced to display different behaviours in terms of cell proliferation and phenotype expression, without the addition of growth factors to the medium.

Human MSCs cultured on type I+II collagen membranes differentiated to a chondroblastic phenotype, with stronger expression of S-100 protein, chondroitin-S and type II collagen compared with controls and with cells grown on type I collagen. These findings agree with recent data (Bosnakovski et al., 2006), supporting the case for a matrix composed of type II collagen for cartilage tissue engineering.

In contrast MSCs cultured on type I collagen + HA membranes differentiated into an osteoblastic phenotype, demonstrating greater ALP activity and stronger positivity for osteonectin and type I collagen than controls and cells grown on type I+II collagen membranes. This finding may be partially related to the modulation of cell behaviour by substrate stiffness (Mattioli-Belmonte et al., 2008) and is in line with recent data underlying the positive effect of mineral components in inducing MSC differentiation to an osteoblastic phenotype (Bigi et al., 2007; Wang et al., 2007). A scaffold matrix composed of type I collagen and $\mathrm{HA}$, providing support for MSC growth without compromising their osteogenic differentiation ability (Shih et al., 2006), may thus be indicated for bone tissue engineering. These data confirm the scope for cell behaviour control by the substrate and encourage the clinical use of different scaffolds to obtain different skeletal tissues.

\section{References}

Banfi A, Bianchi G, Notaro R, Luzzatto L, Cancedda R, Quarto R. Replicative aging and gene expression in long-term cultures of human bone marrow stromal cells. Tissue Eng 2002;8:901-10.

Barry F, Boynton RE, Liu B, Murphy JM. Chondrogenic differentiation of mesenchymal stem cells from bone marrow: differentiationdependent gene expression of matrix components. Exp Cell Res 2001;15:189-200.

Bigi A, Nicoli-Aldini N, Bracci B, Zavan B, Boanini E, Sbaiz F, et al. In vitro culture of mesenchymal cells onto nanocrystalline hydroxyapatite-coated Til3Nbi3Zr alloy. J Biomed Mater Res A 2007;82:213-21.

Bosnakovski D, Mizuno M, Kim G, Takagi S, Okumura M, Fujinaga T. Chondrogenic differentiation of bovine bone marrow mesenchymal stem cells (MSCs) in different hydrogels: influence of collagen type II extracellular matrix on MSC chondrogenesis. Biotechnol Bioeng
2006;93:1152-63.

Bruder SP, Jaiswal N, Haynesworth SE. Growth kinetics, self-renewal and the osteogenic potential of purified human mesenchymal stem cells during extensive subcultivation and following cryopreservation. $\mathrm{J}$ Cell Biochem 1997;64:278-94.

Cancedda R, Dozin B, Giannoni P, Quarto R. Tissue engineering and cell therapy of cartilage and bone. Matrix Biol 2003;22:81-91.

Caplan AI. The mesengenic process. Clinics in Plastic Surgery 1994;21:429-35.

Caterson EJ, Li WJ, Nesti LJ, Albert T, Danielson K, Tuan RS. Polymer/alginate amalgam for cartilage-tissue engineering. Ann N Y Acad Sci 2002;961:134-8.

Chai $\mathrm{C}$, Leong $\mathrm{KW}$. Biomaterials approach to expand and direct differentiation of stem cells. Mol Ther 2007; 15:467-80.

Ciapetti G, Ambrosio L, Marletta G, Baldini N, Giunti A. Human bone marrow stromal cells: In vitro expansion and differentiation for bone engineering. Biomaterials 2006 27:6150-60.

Datta N, Holtorf HL, Sikavitsas VI, Jansen JA, Mikas AG. Effect of bone extracellular matrix synthesized in vitro on the osteoblastic differentiation of marrow stromal cells. Biomaterials 2005;26:9717.

Dominici M, Le Blanc K, Mueller I, Slaper-Cortenbach I, Marini F, Krause $\mathrm{D}$ et al. Minimal Criteria for deifying multipotent mesenchymal stem cells. The International Society for Cellular Therapy position statement. Cytotherapy 2006;8:315-7.

Elisseeff J. Injectable cartilage tissue engineering. Export Opin. Biol. Ther 2004; 4:1849-59.

Gerson SL. Mesenchymal stem cells: no longer second class marrow citizens. Nat Med 1999;5:262-4.

Gigante A, Bevilacqua C, Cappella M, Manzotti S, Greco F. Engineered articular cartilage: influence of the scaffold on cell phenotype and proliferation. J Mater Sci: Mater Med 2003;14:713-6.

Johnstone B, Hering TM, Caplan AI, Goldberg VM, Yoo JU. In vitro chondrogenesis of bone marrow-derived mesenchymal progenitor cells. Exp Cell Res 1998;238:265-72.

Kadiyala S, Young RG, Thiede MA, Bruder SP. Culture expanded canine mesenchymal stem cells possess osteochondrogenic potential in vivo and in vitro. Cell Transplant 1997;6:125-34.

Kassem M, Abdallah BM. Human bone-marrow-derived mesenchymal stem cells: biological characteristics and potential role in therapy of degenerative diseases. Cell Tissue Res 2008;331:157-63. (Epub 2007 Sep 25).

Kipnes J, Carlberg AL, Loredo GA, Lawler J, Tuan RS, Hall D. Effect of cartilage oligomeric matrix protein on mesenchymal chondrogenesis in vitro. Osteoarthritis Cart 2003;11:442-54.

Landi E, Tampieri A, Mattioli-Belmonte M, Celotti G, Sandri M, Gigante $\mathrm{A}$ et al. Biomimetic $\mathrm{Mg}$ - and $\mathrm{Mg}, \mathrm{CO3}-$ substituted Hydroxyapatites: Synthesis, Characterization and in Vitro Behaviour. J Eur Cer Soc 2006;26: 2593-601.

Mastrogiacomo M, Cancedda R, Quarto R. Effects of different growth factors on the chondrogenic potential of human bone marrow stromal cells. Osteoarthritis Cart 2001;9 (SuppIA): S36-40.

Mattioli-Belmonte M, Lucarini G, Virgili L, Biagini G, Detomaso L, Favia $P$ et al. Mesenchymal Stem Cells on plasma deposited Acrylic Acid coatings: an in vitro investigation to improve biomaterial performance in bone reconstruction. J Bioact Compat Polym 2005;20:343-60.

Mattioli-Belmonte M, Vozzi G, Kyriakidou K, Pulieri E, Lucarini G, Vinci $B$ et al. Microarchitectured scaffolds and porous PLGA substrates condition cell morpho-functional behaviour. J Biomed Mat Res A. 2008; 85:466-76.

Muraglia A, Corsi A, Riminucci M, Mastrogiacomo M, Cancedda R, Bianco $\mathrm{P}$ et al. Formation of chondro-osseous rudiment in micromass cultures of human bone-marrow stromal cells. J Cell Sci 2003;116:2949-55.

Peterson L, Minas T, Brittberg M, Nilsson A, Sjogren-Jansson $E$, Lindahl A. Two- to 9-year outcome after autologous chondrocytes transplantation of the knee. Clin Ortop 2000;374:212-34.

Pittinger MF, Mackay AM, Beck SC, Jaiswal RK, Douglas R, Mosca JD et al. Multilineage potential of adult human mesenchymal stem cells. Science 1999;284:143-7.

Ponticiello MS, Schinagl RM, Kadiyala S, Barry FP. Gelatin-based resorbable sponge as a carrier matrix for human mesenchymal stem 


\section{A. Gigante et al.}

cells in cartilage regeneration therapy. J Biomed Mater Res A 2000;52:246-55.

Prockop DJ. Marrow stromal cells as stem cells for non-haematopoietic tissues. Science 1997;276:71-4.

Reyes M, Lund T, Lenvik T, Aguiar D, Koodie L, Verfaillie CM. Purification and ex vivo expansion of postnatal human marrow mesodermal progenitor cells. Blood 2001;98:2615-25.

Shih YR, Chen CN, Tsai SW, Wang YJ, Lee OK. Growth of mesenchymal stem cells on electrospun type I collagen nanofibers. Stem Cells 2006;24:2391-7.

Trubiani 0, Di Primio R, Traini T, Pizzicannella J, Scarano A, Piattelli A et al. Morphological and cytofluorimetric analysis of adult mesenchymal stem cells expanded ex vivo from periodontal ligament. Int J Immunopathol Pharmacol 2005;18:213-21.

Wang H, Li Y, Zuo Y, Li J, Ma S, Cheng L. Biocompatibility and osteo- genesis of biomimetic nano-hydroxyapatite/polyamide composite scaffolds for bone tissue engineering. Biomaterials 2007; 28:333848.

Williams CG, Kim TK, Taboas A, Malik A, Manson P, Elisseeff J. In vitro chondrogenesis of bone marrow-derived mesenchymal stem cells in photopolymerizing hydrogel. Tissue Eng 2003;9:679-88.

Yoo JU, Barthel TS, Nishimura K, Solchaga L, Caplan AI, Goldberg $\mathrm{VM}$ et al. The chondrogenic potential of human bone marrowderived mesenchymal progenitor cells. J Bone Joint Surg Am 1998;80:1745-57.

Younger EM, Chapman MW. Morbidity at bone graft donor sites. J Orthop Trauma 1989;3:192-95.

Zavan B, Giorgi C, Bagnara GP, Vindigni V, Abatangelo G, Cortivo R. Osteogenic and chondrogenic differentiation: comparison of human and rat bone marrow mesenchymal stem cells cultured into polymeric scaffolds. Eur J Histochem 2007;51Suppl 1:1-8. 